\title{
NOTAS ACERCA DE LOS LÍMITES A LA PRETENSIÓN DE CUMPLIMIENTO DEL CONTRATO*
}

\section{Carlos Pizarro Wilson**}

RESUMEN: La ejecución forzada o, como preferiremos llamarle, la pretensión específica en favor del acreedor ante el incumplimiento, debe quedar sometida a ciertos límites si se le considera entre otros remedios a la inejecución del contrato. Estos límites refieren a los ya conocidos asociados a la idea de imposibilidad, otros que corresponde agrupar en términos de estándares y, por último, la facultad de moderar, excluir o fortalecer este remedio por vía convencional. Estas limitaciones contribuyen a delinear la operativa del remedio, otorgándole coherencia en el sistema de sanciones al incumplimiento contractual.

PALABRAS CLAVE: Incumplimiento contractual - pretensión específica - límites.

\section{THOUGHTS ON LIMITS TO CLAIMS FOR CONTRACT PERFORMANCE}

ABSTRACT: Enforcement actions, or as we prefer to call them, the creditor's specific claim in case of breach, should be subject to certain limits if, among other remedies, non-performance is an option. These limits are related to such familiar ideas as impossibility, as well as others that can be organized in terms of standards, and finally, the power to temper, exclude or strengthen this remedy by agreement. These limitations help outline the remedy in operational terms, providing coherence to the system of penalties for breach of contract.

KEY WORDS: Breach of contract - Specific claim - Limits.

\footnotetext{
* $\quad$ Este artículo forma parte del proyecto Principios de la Tutela Ejecutiva del Crédito, Fondecyt Regular no 1111021 y de aquel relativo a la indemnización de perjuicios por incumplimiento contractual no 1120708 . Agradezco los comentarios, observaciones y correcciones que hiciera a este trabajo la profesora Claudia Bahamondes Oyarzún.

Fecha de recepción: 18 de marzo de 2013.

Fecha de aceptación: 2 de enero de 2014.

** Profesor Investigador Facultad de Derecho de la Universidad Diego Portales, Santiago, Chile. Doctor en derecho Universidad Paris II (Panthéon-Assas), Correspondencia a: República 112, Santiago, Correo electrónico carlos.pizarro@udp.cl teléfono (56-2) 26762640.
} 
En Chile se ha ido consolidando, al menos a nivel doctrinal, una manera de entender el fenómeno del incumplimiento contractual despercudido de la culpa, pudiendo el acreedor escoger entre distintas facultades o pretensiones una vez verificada la inejecución contractual. Se trata de una idea cuyas raíces podemos situar en la obra del profesor Morales Moreno $^{1}$, a partir de la profundización del concepto de propósito práctico en la obra de Federico de Castro y $\mathrm{Bravo}^{2}$. Se busca privilegiar su interés, aunque moderado con el principio de la buena fe contractual ${ }^{3}$. Estas ideas han penetrado en la doctrina contemporánea. No son pocos los autores que han acogido en sus escritos la modernización del derecho de los contratos entendido como un sistema de remedios al incumplimiento contractual ${ }^{4}$. Incluso, esto ha originado una nueva nomenclatura

1 Morales Moreno, Antonio Manuel (2006). "Evolución del concepto de obligación en derecho español”, en La modernización del derecho de obligaciones, Cizur Menor (España): Thompson-Civitas, pp. 17-54. El autor establece ahí lo que se estiman son los pilares de la modernización del derecho de los contratos, entre los cuales destaca la noción de incumplimiento, en particular p. 17.

2 De Castro y Bravo, Federico (1991). El negocio Jurídico, Madrid (España): Civitas, pp. 550, en particular, p. 34 y 228. Acerca de la idea de propósito práctico, Morales Moreno, Antonio Manuel (2006). "El "propósito práctico" y la idea de negocio jurídico en Federico de Castro", en La modernización del derecho de obligaciones, Cizur Menor (España): Thompson-Civitas, pp. 323-348.

3 Sobre este asunto, Vidal Olivares, Álvaro (2007). "El incumplimiento de obligaciones con objeto fungible y los remedios del acreedor afectado. Una relectura de las disposiciones del "Código Civil" sobre incumplimiento". En Guzmán Brito, Alejandro (editor científico): El Código Civil de Chile (1855-2005). Trabajos expuestos en el congreso internacional celebrado para conmemorar su promulgación (Santiago, 3-6 de octubre de 2005), Santiago (Chile): LexisNexis, pp. 495-550, p. 495 y ss.; Barros Bourie, Enrique (2008). "Finalidad y alcance de las acciones y los remedios contractuales". En Guzmán Brito, Alejandro (editor científico): Estudios de Derecho Civil III. Jornadas nacionales de derecho civil Valparaiso, 2007, Santiago (Chile): LegalPublishing, pp. 403-428, p. 409 y ss.; Pizarro Wilson, Carlos (2008). "Hacia un sistema de remedios al incumplimiento contractual". En Guzmán Brito, Alejandro (editor científico): Estudios de Derecho Civil III. Jornadas nacionales de derecho civil Valparaiso, 2007, Santiago (Chile): LegalPublishing, pp. 395-402, p. 395 y ss.

4 En una perspectiva desde la teoría del derecho de los contratos, Barcia Lehmann, Rodrigo (2013). "Incidencia de la teoría en la aplicación de la ley y la interpretación e integración del contrato". En Domínguez Hidalgo, Carmen et al. (coordinadores): Estudios de derecho civil VIII. Jornadas nacionales de derecho civil Santa Cruz, 2012, Santiago (Chile): LegalPublishing-Thompson Reuters, pp. 209-232; A propósito de las resolución por anticipación, con abundante información sobre los instrumentos internacionales del derecho de los contratos, Contardo González, Juan Ignacio (2013). "La resolución por anticipación o por incumplimiento previsible. Intento de construcción a partir de los artículos 1826 del Código civil y 147 del Código de comercio". En Domínguez Hidalgo, Carmen et al. (coordinadores): Estudios de derecho civil VIII. Jornadas nacionales de derecho civil Santa Cruz, 2012, Santiago (Chile): LegalPublishing-Thompson Reuters, pp. 267-280; El MIsмо (2012) El perjuicio resolutorio. Delimitación y cuantía de la indemnización de perjuicios consagrada en el artículo 1489 del Código civil en caso de resolución por incumplimiento. Tesis para optar al grado de Doctor en Derecho, Santiago (Chile): (inédita), pp. 392; en el mismo sentido, enmarcando sus escritos en la modernización del derecho de los contratos, Mejías Alonzo, Claudia (2011). El incumplimiento resolutorio en el Código civil, Santiago (Chile): AbeledoPerrot-LegalPublishing Chile, pp. 312; Momberg Uribe, Rodrigo (2010). "El siste- 
acerca de las posibilidades que se abren para el acreedor insatisfecho; a ese conjunto de alternativas se le denomina "remedios frente al incumplimiento contractual". Sin embargo, en este trabajo no se pretende analizar el sistema de remedios frente al incumplimiento contractual, sino que concentrarnos en los límites a uno de ellos: la denominada pretensión de cumplimiento específico o ejecución forzada. Entre los remedios siempre ha destacado la ejecución forzada, que para este movimiento doctrinal se le denomina a través de la expresión "pretensión de cumplimiento" o "pretensión de cumplimiento específico". En este sentido, Díez-Picazo expresa que "la primera medida de reacción que en el orden lógico ocurre es la acción dirigida a obtener el comportamiento omitido y a obtenerlo en forma específica, del mismo modo que debió ser y no fue realizado por el deudor, lo que, naturalmente, es un derecho del acreedor, llamado "pretensión de cumplimiento" a la acción o facultad que se confiere al acreedor para obtener esa finalidad" 5 . Con estas expresiones se intenta diferenciar un aspecto más bien procesal de la voz "ejecución" que situaría el asunto en el terreno del juicio ejecutivo o las vías de ejecución ${ }^{6}$.

En Chile, Claro Solar, utiliza la expresión ejecución forzada: "Si el deudor demora el cumplimiento de la obligación o se resiste y niega a cumplirla, porque la desconoce y viola la palabra empeńada, el acreedor tiene derecho a pedir la ejecución forzada de la obligación, es decir, de requerir la intervención de los tribunales de justicia para que obliguen al deudor, con el auxilio de la fuerza pública, si llegara a ser necesario, que solucione su obligación"7. Aquí se percibe con claridad el aspecto procedimental, aludiendo a la intervención judicial y al uso de la fuerza pública para la obtención de la pretensión. Y luego se asocia esta vía de ejecución con el derecho a perseguir los bienes del deudor previsto en el artículo 2465 del Código civil, conocido como derecho de prenda general. Sin

ma de remedios para el caso de imprevisión o cambio de circunstancias", en Incumplimiento contractual. Nuevas perspectivas, Santiago (Chile): Universidad Diego Portales, pp. 83-105.

5 Dímz-Picazo, Luis (2008) Fundamentos del derecho civil patrimonial. II. Las relaciones obligatorias. $6^{a}$ edición. Cizur Menor: Thompson-Civitas, p. 775.

6 Verdera Server, Rafael (1995). El cumplimiento forzoso de las obligaciones, Bolonia: Real Colegio de Espańa, pp. 21-25. Aunque se reconoce que la vía de ejecución es insoslayable. La pretensión específica exige el impulso de una acción para reclamar la ejecución con el auxilio de los tribunales. Esta necesidad, marca el carácter judicial de la pretensión específica. Por eso, el mismo Díez-Picazo manifiesta que "la acción se dirige a obtener en forma específica la pretensión omitida por el deudor, y cuando el deudor hubiera cumplido solo parcialmente, a obtener aquella parte de la prestación que no ha sido ejecutada", Díez-Picazo (2008) 775. Una mirada procesal en el derecho francés en Piedelièvre, Stéphane (2009) Droit de l'exécution. Paris: Thémis Droit-Puf, pp. 406, p. 157 y ss.

7 Claro Solar, Luis (1937) Explicaciones de derecho civil chileno y comparado. De las obligaciones, II. Santiago: Imprenta Nascimento, p. 691 y ss. 
embargo, esta realización de los bienes se traduce en un pago equivalente de lo debido, alejado de la pretensión específica pactada en el contrato ${ }^{8}$.

Parece, entonces, más apropiado preferir aquella expresión de "cumplimiento específico" 9 , engarzada con la cuestión sustantiva que le permite reclamar al acreedor lo pactado o debido, o aquella utilizada en la doctrina española "la pretensión de cumplimiento"10. En este trabajo utilizaremos esa expresión: cumplimiento específico o pretensión de cumplimiento específico, limitando su análisis a las obligaciones no dinerarias, pues en aquellas en que la prestación es una suma de dinero, la ejecución se traduce en todos los casos en el pago en unidades monetarias si el deudor presenta bienes en su patrimonio. Distinto es el escenario en las obligaciones de hacer y no hacer o, como se prefiere agruparlas hoy, las que no constituyen una pretensión dineraria, pues aquí el cumplimiento difiere de la entrega de dinero, exigiéndose un objeto, una conducta o servicio específico.

La pretensión de cumplimiento constituye una sanción transversal frente a la inejecución contractual ${ }^{11}$. El acreedor exige lo pactado en términos exactos a lo acordado en el contrato, sin sustitución, lo que bajo la resistencia del deudor amerita imponerle el cumplimiento de su compromiso, o en caso de cumplimiento imperfecto, la reparación del producto o servicio, lo que también restablece lo acordado y asumido en el contrato ${ }^{12}$.

Según se entiende, en una perspectiva tradicional del derecho civil, el cumplimiento específico constituye un homenaje a la palabra comprome-

$8 \quad$ Claro Solar (1937) 692 y ss.; lo siguen, Fueyo Laneri, Fernando, (1991) Cumplimiento $e$ incumplimiento de las obligaciones. 2a edición. Santiago: Jurídica, p. 269; Abeliuk MaNASEvich, René (2011) Las obligaciones, t. II. 5a edición. Santiago: Jurídica, p. 797 y ss.; Alessandri R., A.; Somarriva U., Manuel y Vodanovic H., Antonio (2011) Tratado de las obligaciones. 2a edición. Santiago: Jurídica, p. 231 y ss. Todos realizan un análisis procesal de la ejecución de las obligaciones, distinguiendo según se trate de una obligación de dar, hacer o no hacer. Un análisis crítico de la posición tradicional de la doctrina nacional en VIDAL Olivares, Álvaro (2007) "La pretensión de cumplimiento específico y su inserción en el sistema de remedios por incumplimiento en el Código civil”. En Corral Talciani, HernánRodríguez Pinto, María Sara (coordinadores): Estudios de Derecho Civil II. Jornadas nacionales de derecho civil, Olmué 2006, Santiago (Chile): LexisNexis, pp. 517-537, pp. 518 y 520.

9 Morales Moreno (2006) 55 y ss. En Chile, Vidal (2007) 517.

10 Díez Picazo (2008) 775.

11 Para una visión de conjunto en Europa: Ancel, P., Fauvarque-Cosson, B., Wintgen, R. (2006). "Regards comparatistes sur l'exécution forcée en nature". Revue des Contrats, no 2, pp. 529-542, p. 529 y ss. La expresión "sanción” genera ciertas reticencias para aquellos más apegados a la idea absolutamente neutra del incumplimiento contractual. Pero hay que observar que el cumplimiento específico requiere la intervención judicial ante la resistencia del deudor.

12 Acerca de la jerarquía entre los remedios frente al incumplimiento, BaHAmondes Oyarzún, Claudia (2011) "Concurrencia de la indemnización de daños y la pretensión de cumplimiento específico frente al incumplimiento contractual”. En de la Maza Gazmuri, Iñigo (coordinador): Incumplimiento contractual. Nuevas perspectivas, Santiago: Universidad Diego Portales, pp. 235-262, en particular, p. 241 y ss. 
tida, lo que sería el reflejo exacto de la fuerza obligatoria del contrato. Sobre esto ya se ha dicho bastante ${ }^{13}$. En efecto, la relación entre el cumplimiento específico y la fuerza obligatoria del contrato dejaría a la primera en una situación de preferencia de cómo debemos entender las sanciones al incumplimiento contractual ${ }^{14}$.

No puede desconocerse que la pretensión específica "corresponde más exactamente con el contenido del derecho de crédito lesionado por el incumplimiento. Es, por decirlo así, la única pretensión que se orienta a reintegrar en su natural contenido al derecho lesionado"15. Todos los otros remedios difieren de lo que se quiso al contratar, buscando una satisfacción alternativa para el acreedor.

El derecho a la pretensión específica supone, necesariamente, que el deudor no ha ejecutado su obligación o lo ha hecho en forma imperfecta; para el acreedor esta situación significa una severa insatisfacción. Luego, el centro de atención se coloca, a propósito de este remedio, en forzar al deudor a cumplir. Pero no siempre es posible o querido, debiendo recurrirse al pago por equivalencia, es decir, la sustitución en dinero de la prestación imposible o, incluso, puede resultar imprescindible demandar, además, la indemnización por el retardo en la ejecución y la reparación de los perjuicios que se hayan generado como consecuencia del incumplimiento; por último, puede cobrar fuerza la resolución para deshacer lo acordado.

Sobre el lugar que debe cumplir el cumplimiento específico pareciera existir controversia, encontrándose los modelos jurídicos en una cierta tensión. Mientras la jurisprudencia y doctrina francesa abogan por el cumplimiento específico, erigiéndolo como la sanción fundamental ${ }^{16}$, otros sistemas, como el espańol o aquellos más cercanos al mundo anglo-

13 Un análisis detallado de esta cuestión en Laithier, Yves-Marie (2004) Étude comparative des sanctions de l'inexécution du contrat. Paris: LGDJ, pp. 33 y ss.; en Chile también Vidal (2007) "la pretensión...", 517 y ss.

14 Acerca de la pretendida jerarquía del cumplimiento específico respecto a los otros remedios, por todos y en clave crítica, BAHAmondes Oyarzún (2010), pp. 237 y ss. La autora se explaya en explicar la raigambre histórica vinculada a la stipulatio que explicaría esta comprensión que asimila el cumplimiento específico al pago en las obligaciones específicas de cuerpo cierto.

15 Díez-Picazo, L, Roca Trías, E. y Morales Moreno, A. M. (2002) Los principios del derecho europeo de contrato. Madrid: Civitas, pp. 334-335.

16 Pascal, Ancel (2008) "Points de vue convergents sur le projet de réforme du Droit des contrats", Semaine Juridique, 48, 1, pp. 18 y ss., en particular, p. 22, en que se hace referencia al fallo de la Corte de Casación que obligó destruir y reconstruir una casa, que presentaba una diferencia de 33 centímetros de elevación, en relación con la propuesta inicialmente contratada. A favor de una apreciación del carácter adecuado de la sanción: Gridel, J. P. (2008) "Les sanctions civiles de l'inexécution du contrat imputable au débiteur: état des lieux", Semaine Juridique, 21, 1, p. 13, en particular, p. 15. Por un visión neutra véase : Stoffel-Munck, Ph. (2009) "Exécution et inexécution du contrat", Revue des Contrats, 1 p. 332, en particular, p. 336. 
sajón, privilegian la indemnización de perjuicios, arrinconando la pretensión específica a casos muy limitados ${ }^{17}$.

Con todo, aun en los sistemas que privilegian el cumplimiento específico por sobre los otros remedios o acciones frente al incumplimiento, no se dejan de reconocer ciertos límites. Estos muestran que, más que una disputa entre modelos o sistemas que erijan o subyuguen la pretensión específica, se logra un consenso a través de estándares que son más o menos cercanos a los diversos sistemas legales, orientados a delinear los contornos de la pretensión específica. Si bien este remedio es adecuado para los problemas de incumplimiento contractual a merced del acreedor insatisfecho, es necesario considerar estos límites a su ejercicio. Para su análisis, hay que distinguir aquellos que radican en una imposibilidad y los otros que relativizan el derecho mediante estándares. En último término, cabe interrogarse si en el ejercicio de la libertad contractual puede moderarse o excluirse la facultad al cumplimiento específico. A estas tres cuestiones, fundamentales para delinear los contornos de la pretensión específica, me referiré en lo que sigue.

\section{1) LA IMPOSIBILIDAD COMO LÍMITE A LA PRETENSIÓN ESPECÍFICA}

En nuestro Código civil el cumplimiento específico no admite límites específicos diversos a la "consecuencia de la naturaleza de las cosas" 18 . Los límites solo atingen a las obligaciones no dinerarias, pues aquellas pecuniarias, por su esencia, se traducen en dinero.

La idea de imposibilidad puede radicar en la extinción del bien en cuestión, siendo este irremplazable, o puede involucrar la inviabilidad de forzar físicamente al deudor a la prestación. Mientras en el primer caso la imposibilidad se explica por la desaparición material del objeto, único en su especie; en la otra, se revela la naturaleza intuito personae de la obligación que requiere la participación física del deudor, al que no puede compelerse o forzar de manera física a ejecutar la obligación.

17 En términos generales, Díez Picazo, Roca Trias, Morales Moreno (2002) 333 y ss. "En el derecho inglés existe un principio según el cual una persona que invoca el incumplimiento de un contrato no puede compeler a la otra parte contratante (el deudor) al cumplimiento efectivo del mismo, sino que tiene que conformarse con una compensación económica”. Solo en algunos casos en los que la indemnización de daños ha podido ser considerada como un remedio inadecuado, los tribunales han concedido a decree of specific performance o injuction, que puede llegar a imponer la ejecución del contrato. Un análisis comparativo exhaustivo, incluyendo el sistema francés, norteamericano e inglés en Laithier (2004) 33 y ss. y p. 381 y ss. Un análisis comparativo más moderado en ANCEL-FAuvarque-Cosson (2006) 529.

18 Los límites refieren a la idea de imposibilidad natural o material, pensando en un bien específico irremplazable, lo que en la actualidad es infrecuente, Díez-Picazo (2008) 775; en Chile, Vidal (2007). 517 y ss. 
La destrucción del bien específico o la imposibilidad del deudor de ejecutar lo pactado, constituyen también límites compartidos con la resolución. Así ocurre si la cosa desapareció o fue transferida a un tercero de buena fe, siendo inaplicable el artículo 1490 o constaba en título la condición, obstaculizando el ejercicio de la acción contra el tercero conforme el artículo 1491 del Código civil. Ahí solo queda espacio para la reparación por equivalencia y la indemnización de los perjuicios ocasionados ${ }^{19}$.

En esta situación la imposibilidad es material, no existiendo medios para forzar la naturaleza o las leyes de la física. Ha sido el límite tradicional al cumplimiento específico bajo el aforismo de que nadie está obligado a lo imposible. Fuera de los casos extravagantes en que concurre este tipo de imposibilidad natural, también se considera imposible lo que no se puede realizar conforme a derecho. Si el bien fue transferido por el demandado, nada podrá realizar este que involucre la satisfacción de su acreedor. Ocurre en casos que el promitente vendedor enajena a un tercero y, salvo la hipótesis de interferencia contractual, nada puede hacer el promitente comprador en relación con el tercer adquirente, ni tampoco puede exigir la pretensión específica al promitente vendedor. Acá solo cabrá la indemnización de perjuicios acompañada o no de la resolución del contrato.

La otra situación considera que el ser humano detenta derechos que no pueden afectarse, forzándolo mediante una coacción física a ejecutar una obligación. Desde antiguo así se ha entendido. Claro Solar ya manifestaba que "Si se tratara de un hecho personal del deudor, como si este fuera un actor que se obligó a representar un papel en una tragedia, o un pintor famoso que se obligó a pintar un cuadro o a hacer un retrato, no podría forzársele a ejecutar el hecho a que se obligó si se resiste" 20 .

En el caso que se requiera una compulsión física contra el deudor, el cumplimiento específico queda vetado. En caso contrario, nada impide su ejecución, lo que se verifica si la cosa puede obtenerse por la fuerza pública, si la contravención a la obligación de no hacer puede destruirse o aún si es necesario firmar un documento o suscribir un contrato ${ }^{21}$. Así lo expresa en forma elocuente una autora refiriéndose al derecho francés "En efecto en este caso la intervención de la fuerza pública para hacer ejecutar implicaría normalmente el ejercicio de una compulsión física a la cual nuestro derecho repugna cuando se trata de hacer ejecutar obligacio-

19 Peñailillo Arévalo, Daniel (2003) Obligaciones. Teoría general y clasificaciones. La resolución por incumplimiento, Santiago (Chile): Jurídica, pp. 453 y ss.

Claro Solar (1937) 697; Fueyo Laneri (1991) 269.

Viney, G. (2001) "Exécution de l'obligation, faculté de remplacement et réparation en nature en droit français". En Fontaine, Marcel y Viney, Geneviève (directores): Les sanctions de l'inexécution des obligations contractuelles. Études de droit comparé, Bruxelles-Paris: Bruylant-LGDJ, p. 185 y ss. 
nes puramente civiles" 22 . Aquí corresponde que opere la sustitución de la fuerza sobre la persona, por aquella que debe ejercerse sobre el patrimonio del deudor.

Pero, aun en estos casos en que el derecho a la integridad física anula el cumplimiento específico, resulta necesario establecer ciertos mecanismos indirectos que lo impulsan. Entre ellos está la denominada astreinte o multas que puede fijar el juez para compeler a la ejecución. Este mecanismo está ausente en nuestra legislación. Sin embargo, no deben abrigarse tantas expectativas en la compulsión a través de las multas, pues incluso dicha ejecución puede ser insatisfactoria una vez verificada, sobre todo si se trata de una prestación personal, lo que puede desembocar en otro litigio sobre el cumplimiento satisfactorio o incompleto de la prestación.

Todavía es necesario considerar que la imposibilidad no es una causal, necesariamente, de extinción de la obligación. Bien puede ocurrir que sea transitoria, lo que permitirá restablecer la obligatoriedad del vínculo una vez recuperada la normalidad de la relación ${ }^{23}$. Cabe diferenciar el efecto transitorio de la fuerza mayor como causal de exoneración temporal de aquel efecto extintivo originado en la imposibilidad permanente coincidente con la pérdida de la cosa debida. Por lo mismo esa imposibilidad transitoria no constituye un límite, sino tan solo una suspensión temporal de la ejecución mientras se restablecen las circunstancias.

\section{2) LOS ESTÁNDARES CONTRACTUALES COMO LÍMITE A LA PRETENSIÓN ESPECÍFICA}

Diversos estándares se han propuesto como límite a la pretensión específica. Una primera aproximación es económica y la otra se vincula al abuso del derecho.

Es usual hoy plantear que la pretensión específica no debiera prosperar si tiene como consecuencia un costo desproporcionado para el deudor, atendidas las circunstancias del contrato y el interés del acreedor.

Esos mismos límites, que se han ido decantando en los procesos de reforma al derecho de los contratos en otros sistemas legales, además, se recogen en los PECL ${ }^{24}$. En sentido análogo se pronuncia el Draft Common Frame of Reference -DCFR-, en cuyo artículo III.-3.302 recoge la misma idea ${ }^{25}$. Los límites previstos son que la ejecución resultara contra-

\footnotetext{
VINEY (2001) 186.

Díez-Picazo, Roca Trías y Morales Moreno (2002) 340.

Díez-Picazo, Roca Trías y Morales Moreno (2002) 337 y ss.

Cabe recordar aquí que en algunos sistemas legales la ejecución forzada "specific performance" solo puede ser requerida en la hipótesis en que la indemnización sea un remedio inadecuado. Sin embargo, esta posición es más bien aislada en los países europeos en que la
} 
ria a derecho o imposible, que aquella sea "no razonable" o excesivamente costosa o aparezca revestida de un carácter personalísimo que haga "no razonable" su ejecución forzada. En general, podría decirse sin incurrir en error que el DCFR insiste en los límites ya previstos en los PECL ${ }^{26}$.

En lo que refiere a las obligaciones no dinerarias, que interesan acá, debe considerarse el artículo 9.102 de los PECL, realiza un consenso entre el modelo anglosajón y aquel continental ${ }^{27}$. Luego de considerar la facultad para solicitar la pretensión específica, se estipulan como límites la imposibilidad, el esfuerzo o gasto no razonable, las obligaciones personalísimas de hacer y la operación de reemplazo alternativa más razonable. Lo mismo podemos verificar en los Principios Unidroit, con la particularidad que se agrega como límite que aparezca en forma razonable que se obtenga por el acreedor un resultado satisfactorio recurriendo a otro remedio $^{28}$.

En la hipótesis que la pretensión específica suponga gastos desproporcionados o un esfuerzo desmesurado, el deudor podría optar por la indemnización de los perjuicios aun contra la voluntad del acreedor ${ }^{29}$. No se trata aquí solo que se trate de una cuestión financiera, ni tampoco cabe confundirla con la imprevisión. Debe existir una justificación importante para afectar la elección del acreedor, debiendo conformarse con la entrega de esta suma en equivalente. En el DCFR se entrega como ejemplo la venta de un yate que mientras se dirigía para su entrega al domicilio del comprador sufre un accidente, lo que significa que si se rescatara del fondo del mar y se pagara conforme lo pactado sería extremadamente gravoso para el deudor, siendo que el comprador podría conformarse con la indemnización. En este caso debiéramos aceptar la alternativa de indemnización. Conforme aparece, también, en los PECL. La satisfacción alternativa más barata no difiere en gran medida del límite económico bajo el estándar de lo razonable [Apartado d) del art. 9.102(2) PECL]. Se trata de dilucidar si se refiere solo a la operación de reemplazo o a otros remedios al incumplimiento. En el comentario al precepto se admite que

specific performance constituye un remedio ordinario frente al incumplimiento. Véase Denis, Philippe, "Book III performance and non-performance of obligations and corresponding rights in the DCFR", en Sagaert, Vicent, Storme, Matthias E. And Terryn, Evelyne (eds), The Draft Common Frame of Reference: national and comparative perspectives, CambridgeAntwerp-Portland (United Kingdom): Intersentia Publishing Ltd, 2012, pp. 35-52, en particular, p. 40 y 41 .

26 Véase http://ec.europa.eu/justice/contract/files/european-private-law_en.pdf visitada el 15 de octubre de 2013, en particular p. 850.

27 Díez-Picazo, Roca Trías y Morales Moreno (2002) 340 y ss.

28 Artículo 7.2.2 Principios Unidroit.

29 Díez-Picazo, Roca Trías y Morales Moreno (2002) 341. 
pueda tratarse de otro remedio. Podría ser así la indemnización, siendo de cargo del deudor acreditar lo razonable de la sustitución ${ }^{30}$.

Otro aspecto a considerar para evaluar la improcedencia del cumplimiento específico es la falta de utilidad para el acreedor, atendido el interés contractual. Para esto podría ser útil recurrir a la idea de propósito práctico del contrato. Si la pretensión de cumplimiento específico no abriga coincidencia con el propósito plasmado en el contrato, siendo posible satisfacerlo con la indemnización o, incluso la resolución, podríamos estar dispuestos a desecharla. Se trata de dilucidar qué interés las partes ingresaron al contrato ${ }^{31}$. Lo que cabe relacionar es el o los intereses razonablemente integrados al contrato y la insatisfacción de los mismos.

La idea de "insatisfacción del interés negocial" nos ayuda a delimitar si estamos frente a una frustración del fin del contrato que amerita la procedencia de la ejecución específica de la prestación o, en cambio, puede obtenerse por otras alternativas. De ahí que deba rehuirse una interpretación voluntarista del contrato dando espacio a aquella más objetiva anclada en el propósito práctico del mismo.

Debe considerarse aquí la relación necesaria entre el derecho del acreedor a escoger el remedio que más se conforme a su interés, pero exigiéndosele racionalidad en la gestión de dichos remedios. Acá el límite nos lleva a la noción de minimización del daño, no pudiendo el acreedor ejercer un remedio que, de manera desproporcionada, signifique una situación extremadamente gravosa para el deudor, en circunstancias en que podría, en términos objetivos y abstractos, quedar satisfecho con otra solución alternativa o sustitutiva. El ejemplo que aparece en el DCFR ilustra esta idea. Si una compañía arrendó un inmueble a una empresa minera comprometiéndose esta a restaurar el terreno una vez expirado el contrato y, es cierto que la propietaria del terreno lo arrendó al ejército para realizar entrenamiento con tanques, la exigencia de satisfacer la obligación por vía del cumplimiento específico aparece como desproporcionada, siendo que no le generará utilidad alguna. En este caso parece más razonable atendido el interés plasmado en el contrato que se proceda a la indemnización de los gastos que significaría la restauración del terreno.

Estos límites económicos, relativos a la desproporción en la exigencia del cumplimiento específico o la alternativa de ejecución menos onerosa, para aplicarse en Chile, en principio, requerirían una reforma legal. Sin perjuicio de la necesidad de afrontar esa tarea mayor, en la que podamos articular de mejor manera los remedios al incumplimiento contractual, erigiendo al acreedor como centro de interés, solo a partir de un estándar

30 Díez-Picazo, Roca Trías y Morales Moreno (2002) 346.

31 Morales Moreno (2006). "El "propósito práctico" y la idea de negocio jurídico en Federico de Castro", en La modernización del derecho de obligaciones, Cizur Menor (Espańa): Thompson-Civitas, pp. 323-348, en particular p. 325. 
o cláusula general podría estimarse viable la introducción de ese límite económico a la pretensión de cumplimiento específico. Tratándose del derecho continental, el estándar que podría usarse es el abuso del derecho.

Si bien el acreedor tiene la facultad de ejercer el remedio que mejor le parezca, no puede abusar de esa prerrogativa ${ }^{32}$. Es el caso en que el cumplimiento es extremadamente oneroso, contrastando con el menor interés del acreedor a la prestación en natura. En este caso sería más apropiado acoger la indemnización de perjuicios, con efectos económicos menos nocivos para el deudor. La teoría del abuso del derecho, con mayor tradición en el derecho continental, podría ser el recipiente que justificara los límites asociados al cumplimiento excesivamente oneroso, la operación de reemplazo u otros remedios o, todavía, el ejercicio en un contexto temporal desproporcionado. No pretendo aquí agotar el criterio relativo al abuso del derecho ${ }^{33}$, sino que solo delinear su comprensión como parámetro para admitir los límites a la pretensión de cumplimiento específico. En términos simples el abuso del derecho consiste en el uso excesivo de una prerrogativa jurídica ${ }^{34}$. En una reciente sentencia de la Corte de apelaciones de Santiago, siguiendo la doctrina de Rodríguez Grez, se ha llevado a cabo el intento de definirlo como:

“...el exceso o desviación del interés jurídicamente protegido por el derecho positivo... Y por interés debe entenderse la "representación de un provecho que es legítimo satisfacer" 35 .

En este caso se convoca a los jueces a una tarea tradicional, constitutiva de un ejercicio de ponderación entre el derecho al cumplimiento específico y la alternativa a otros remedios que le permitirían satisfacer la finalidad o motivo que lo indujo a celebrar el contrato, lo que quedaría plasmado en el propósito práctico del contrato.

En suma, recurrir a la teoría del abuso del derecho, permitiría que los jueces al decidieran si prospera el cumplimiento específico o, en cambio, concurre otra vía remedial más propicia en atención a la ponderación del interés contractual. Con todo, no se nos escapa que el juez no está habilitado en nuestro sistema procesal civil a sustituir la acción del demandante, por lo que el ejercicio abusivo de la pretensión específica se traduciría en el rechazo de la demanda.

\footnotetext{
32 Viney (2001) 183.

33 En Chile, Rodríguez Grez, Pablo (2004), El abuso del derecho y el abuso circunstancial, Santiago (Chile): Jurídica, pp. 128 y ss.

34 Véase en general acerca de la teoría, Авваs, Karimi (2001). Les clauses abusives et la théorie dec l'abus du droit, Paris (Francia): LGDJ, pp. 28 y ss.

35 Cita online: CL/JUR/2247/2013; 66415, Corte de apelaciones de Santiago, 11 de octubre de 2013, Rol 5066-2011.
} 


\section{3) CUMPLIMIENTO ESPECÍFICO Y LIBERTAD CONTRACTUAL}

Por último, es posible interrogarse si por la vía convencional pueden establecerse límites al derecho al cumplimiento específico. Se trata de un asunto que no ha sido, a nuestro entender, explorado en la doctrina nacional. Esto impide recurrir a la opinión de autores locales. El cuestionamiento surge para determinar si el cumplimiento específico asume una naturaleza de orden público. En otros términos, si considerando la relevancia para el acreedor de la pretensión específica, asociada a la noción de obligación, debiera vetarse a los contratantes la posibilidad de excluir la pretensión específica por vía convencional ${ }^{36}$. Nada obsta a que el cumplimiento específico sea fortalecido a través de otras cláusulas que impulsan la ejecución, ya sea la cláusula penal o aquellas de retención a favor del acreedor. Como es obvio, el derecho dispositivo también contempla este tipo de mecanismos, por ejemplo la excepción de contrato no cumplido. Esta realidad difiere del derecho inglés, en el cual, aun contra cláusula expresa, el juez puede rechazar la specific performance. Así se desprende de su carácter de equidad, pudiendo el juez otorgar o rechazar este remedio sin quedar vinculado por el contrato ${ }^{37}$. Menos claridad concurre al momento de averiguar si puede limitarse su ejercicio, establecer condiciones más gravosas o, simplemente, excluir la posibilidad de cumplimiento específico, dejando abierta solo la acción resolutoria o aquella indemnizatoria. Sobre esto no existen textos legales, ni tampoco aparece resuelto en los modelos europeos de contratos supranacionales. Ninguno de los textos usuales, PECL, DCFR y Unidroit aluden a este asunto. La exclusión del cumplimiento específico significaría que el acreedor, en caso de incumplimiento, no podría exigir la prestación, sino que solo otros remedios diversos: resolución, indemnización o ambos. Nada impide, y es usual en la práctica, la renuncia a la acción resolutoria, pero menos evidente resulta justificar que no pueda reclamarse lo que se pactó. En cierta medida el deudor no estaría obligado, siendo solo responsable del incumplimiento ${ }^{38}$; no podría exigirse el cumplimiento, aunque sí existen consecuencias vinculadas a la inejecución, entendiéndose al deudor responsable. Es lo que ocurre, por lo demás, tratándose del pacto comisorio calificado o la cláusula resolutoria expresa. Si uno considera que el efecto resolutorio opera por la simple inejecución, no habría instancia o posibilidad para exigir el cumplimiento. Al operar la resolución con prescindencia de la

Delebecque, Philippe (2006) “L'exécution forcée”. Revue des Contrats. 2, pp. 99-103, p. 100. Ancel-Fauvarque-Cosson (2006), 539.

Barros Bourie, Enrique (2007) "La diferencia entre "estar obligado" y "ser responsable". En Corral Talciani, Hernán-Rodríguez Pinto, Ma Sara (coordinadores): Estudios de Derecho Civil II. Jornadas nacionales de derecho civil Olmué, 2006, Santiago (Chile): LexisNexis, pp. 721-752. 
voluntad de las partes, resulta imposible demandar la prestación específica, salvo cuestionamiento de la resolución automática. Todavía, si consideramos el cumplimiento específico como un derecho o facultad, nada obsta a su renuncia en pleno ejercicio de la libertad contractual, siendo conforme al artículo 12 del Código civil.

En suma, nos manifestamos a favor de la validez de cláusulas que excluyan la pretensión específica por vía contractual. Existiendo controversia sobre el alcance de la libertad contractual en relación con el cumplimiento específico, debiera considerarse una reforma legal que integrara este aspecto.

\section{4) ConClusión}

Un tema hasta ahora ignorado por la doctrina nacional ha sido aquel de los límites al cumplimiento específico del contrato. La acción para requerirlo ha sido fundada como una consecuencia obvia de la fuerza obligatoria del contrato, erigiendo este remedio en una jerarquía superior a los otros.

Es probable que estos límites al cumplimiento específico puedan reducirse solo a la imposibilidad, apareciendo la distinción más pedagógica que práctica, sin perjuicio que el contenido de estos límites debe ser integrado por los jueces ${ }^{39}$. No obstante, el desarrollo dogmático de estos permite delinear de mejor forma los contornos de la antigua reina entre los remedios al incumplimiento contractual.

Sin duda la regulación actual del cumplimiento específico omite consideraciones económicas al obviar el límite de su procedencia para la hipótesis que signifique un costo desmesurado para el deudor ${ }^{40}$. Los instrumentos internacionales recurrentes en el derecho de los contratos muestran un cierto consenso en la necesidad de introducir un límite a la pretensión específica. Parece necesario que este estándar sea considerado, lo que no solo atinge al ejercicio de la facultad, sino que afecta los elementos propios de su procedencia. Existe aquí una relación íntima con el deber de minimizar el daño que debe ampliarse a la gestión razonable, exenta de abuso, de los remedios dispuestos a favor del acreedor ${ }^{41}$. Es esa gestión razonable de los remedios que permite asegurar sus límites, lo que no solo debe entenderse como una cuestión económica, sino que

LAITHIER (2004) 155.

LAITHIER (2004) 156.

Artículo 9:102 letra d) de los PEDC. relativo a las obligaciones no dinerarias; sobre esto: Díez-Picazo, Roca Trías y Morales Moreno (2002) 345. Para Francia, Jourdain, Patrice (2007) "Présentation des dispositions de l'avant-projet sur les effets de la responsabilité". Revue des Contrats, 7, 1, pp. 141 ss. 
importa determinar que la finalidad del contrato sea posible satisfacerla por otras vías.

Por último, un aspecto en que no ha existido preocupación doctrinal, es la posibilidad de las partes de convenir sobre las condiciones y efectos del cumplimiento forzado, lo que amerita no solo admitirlo, sino que una reforma legal que explicite la posibilidad ${ }^{42}$.

La aceptación de estos límites al ejercicio de las pretensión específica constituye un compromiso equilibrado entre el principio de respetar la palabra dada -fuerza obligatoria del contrato-, y la protección del interés del deudor ${ }^{43}$.

\section{Bibliografía Citada}

- Abbas, Karimi (2001). Les clauses abusives et la théorie dec l'abus du droit, Paris (Francia): LGDJ.

- Abeliuk Manasevich, René (2011) Las obligaciones, t. II. 5a edición. Santiago: Jurídica.

- Alessandri R., A.; Somarriva U., Manuel y Vodanovic H., Antonio (2011) Tratado de las obligaciones. 2a edición. Santiago: Jurídica.

- Ancel, P. Fauvarque-Cosson, B. Wintgen, R. (2006). "Regards comparatistes sur l'exécution forcée en nature". Revue des Contrats, no 2, pp. 529-542.

- Bahamondes Oyarzún, Claudia (2011) “Concurrencia de la indemnización de daños y la pretensión de cumplimiento específico frente al incumplimiento contractual". En De la Maza Gazmuri, Iñigo (coordinador): Incumplimiento contractual. Nuevas perspectivas, Santiago: Universidad Diego Portales, pp. 235-262.

- Barcia Lehmann, Rodrigo (2013). "Incidencia de la teoría en la aplicación de la ley y la interpretación e integración del contrato". En Domínguez Hidalgo, Carmen et al. (coordinadores): Estudios de derecho civil VIII. Jornadas nacionales de derecho civil Santa Cruz, 2012, Santiago (Chile): LegalPublishing-Thompson Reuters, pp. 209-232.

42 Laithier (2004) 158. El autor desarrolla el tema analizando la viabilidad de una cláusula impositiva del cumplimiento forzado o, por el contrario, una que la excluya en forma perentoria.

43 Una opinión moderada y sin compromiso en Meкki Amrani, S. - Fauvarque-Cosson, B. (2008) "Droit des contrats". Revue Dalloz, 42, pp. 2965 ss., en particular, p. 2968, en que se interrogan sobre el cuestionamiento que causaría la excepción a propósito de la ejecución forzada, lo que solo podrá resolverse al conocer las decisiones de la jurisprudencia. 
- Barros Bourie, Enrique (2007) "La diferencia entre "estar obligado" y "ser responsable". En Corral Talciani, Hernán-Rodríguez Pinto, Ma Sara (coordinadores): Estudios de Derecho Civil II. Jornadas nacionales de derecho civil Olmué, 2006, Santiago (Chile): LexisNexis, pp. 721-752.

- Barros Bourie, Enrique (2008). "Finalidad y alcance de las acciones y los remedios contractuales". En Guzmán Brito, Alejandro (editor científico): Estudios de Derecho Civil III. Jornadas nacionales de derecho civil Valparaiso, 2007, Santiago (Chile): LegalPublishing, pp. 403-428.

- Claro Solar, Luis (1937) Explicaciones de derecho civil chileno y comparado. De las obligaciones, II. Santiago: Imprenta Nascimento.

- Contardo González, Juan Ignacio (2013). "La resolución por anticipación o por incumplimiento previsible. Intento de construcción a partir de los artículos 1826 del Código civil y 147 del Código de comercio”. En Domínguez Hidalgo, Carmen et al. (coordinadores): Estudios de derecho civil VIII. Jornadas nacionales de derecho civil Santa Cruz, 2012, Santiago (Chile): LegalPublishingThompson Reuters, pp. 267-280.

- Contardo González, Juan Ignacio (2012). El perjuicio resolutorio. Delimitación y cuantía de la indemnización de perjuicios consagrada en el artículo 1489 del Código civil en caso de resolución por incumplimiento. Tesis para optar al grado de Doctor en Derecho, Santiago (Chile): (inédita).

- De Castro y Bravo, Federico (1991). El negocio Jurídico, Madrid (España): Civitas.

- DíEz-Picazo, Luis (2008) Fundamentos del derecho civil patrimonial. II. Las relaciones obligatorias. $6^{a}$ edición. Cizur Menor: ThompsonCivitas.

- Díez-Picazo, L, Roca Trías, E. y Morales Moreno, A. M. (2002) Los principios del derecho europeo de contrato. Madrid: Civitas.

- Fueyo Laneri, Fernando, (1991) Cumplimiento e incumplimiento de las obligaciones. $2^{\mathrm{a}}$ edición. Santiago: Jurídica.

- Delebecque, Philippe (2006) "L'exécution forcée". Revue des Contrats. 2, pp. 99-103.

- Genicon, Thomas (2009) "Observations sur le projet de réforme du Droit des contrats", Petites Affiches, 31, pp. 80-101.

- Gridel, J. P. (2008) "Les sanctions civiles de l'inexécution du contrat imputable au débiteur: état des lieux", Semaine Juridique, 21, 1, pp. 11-25.

- Jourdain, Patrice (2007) "Présentation des dispositions de l'avantprojet sur les effets de la responsabilité". Revue des Contrats, 7, 1, pp. 141-150. 
- Laithier, Yves-Marie (2004) Etude comparative des sanctions de l'inexécution du contrat. Paris: LGDJ.

- MejÍas Alonzo, Claudia (2011). El incumplimiento resolutorio en el Código Civil, Santiago (Chile): AbeledoPerrot-LegalPublishing Chile.

- Mekri Amrani, S. - Fauvarque-Cosson, B. (2008) "Droit des contrats". Revue Dalloz, 42, pp. 2965-2974.

- Momberg Uribe, Rodrigo (2010). "El sistema de remedios para el caso de imprevisión o cambio de circunstancias”, en Incumplimiento contractual. Nuevas perspectivas, Santiago (Chile): Universidad Diego Portales, pp. 83-105.

- Morales Moreno, Antonio Manuel (2006). La modernización del derecho de obligaciones. Cizur Menor:Thompson-Civitas.

- Morales Moreno (2006). "El "propósito práctico" y la idea de negocio jurídico en Federico de Castro", en La modernización del derecho de obligaciones, Cizur Menor (España): Thompson-Civitas, pp. 323-348.

- Pascal, Ancel (2008) "Points de vue convergents sur le projet de réforme du Droit des contrats", Semaine Juridique, 48, 1, pp. 18-24.

- Peñailillo Arévalo, Daniel (2003) Obligaciones. Teoría general y clasificaciones. La resolución por incumplimiento, Santiago (Chile): Jurídica.

- Piedelièvre, Stéphane (2009) Droit de l'exécution. Paris: Thémis Droit-Puf, pp. 406.

- Pizarro Wilson, Carlos (2008). "Hacia un sistema de remedios al incumplimiento contractual”. En Guzmán Brito, Alejandro (editor científico): Estudios de Derecho Civil III. Jornadas nacionales de derecho civil Valparaiso, 2007, Santiago (Chile): LegalPublishing, pp. 395-402.

- Rodríguez Grez, Pablo (2004), El abuso del derecho y el abuso circunstancial, Santiago (Chile): Jurídica.

- Stoffel-Munck, Ph. (2009) "Exécution et inexécution du contrat", Revue des Contrats, 1 pp. 332-343.

- Vidal Olivares, Álvaro (2007). "El incumplimiento de obligaciones con objeto fungible y los remedios del acreedor afectado. Una relectura de las disposiciones del "Código Civil" sobre incumplimiento”. En Guzmán Brito, Alejandro (editor científico): El Código Civil de Chile (1855-2005). Trabajos expuestos en el congreso internacional celebrado para conmemorar su promulgación (Santiago, 3-6 de octubre de 2005), Santiago (Chile): LexisNexis, pp. $495-550$.

- Vidal Olivares, Álvaro (2007) “La pretensión de cumplimiento específico y su inserción en el sistema de remedios por incumplimiento en el Código civil". En Corral Talciani, HernánRodríguez Pinto, María Sara (coordinadores): Estudios de Derecho 
Civil II. Jornadas nacionales de derecho civil Olmué 2006, Santiago (Chile): LexisNexis, pp. 517-537.

- Viney, G. (2001) "Exécution de l'obligation, faculté de remplacement et réparation en nature en droit français". En Fontaine, Marcel y Viney, Geneviève (directores) : Les sanctions de l'inexécution des obligations contractuelles. Études de droit comparé, Bruxelles-Paris: Bruylant-LGDJ, pp. 185-203. 